\title{
Heat Release Distribution in a Dual-Mode Scramjet Combustor - Measurements and Modeling
}

\author{
Daniel J. Micka*, Sean M. Torrez*, and James F. Driscoll ${ }^{\dagger}$ \\ University of Michigan, Ann Arbor, MI, 48109, USA
}

\begin{abstract}
To model the performance and operability limits of a dual-mode scramjet engine, the heat release distribution must be accurately predicted. This distribution controls the thermal choking point, and thus the profiles of pressure, Mach number, and heat transfer in the engine. The current research effort consists of two parts: measurement of heat release distributions from $\mathrm{OH}^{*}$ and $\mathrm{CH}^{*}$ in a dual-mode combustor, and development of a 1-D scramjet engine performance model. A dual-mode combustor with transverse wall fuel injection and a cavity flameholder is investigated experimentally for air stagnation temperatures of 1270-1520K. The upstream region of the heat release distribution depends on the flame stabilization and spreading. The flame length and downstream region of heat release distribution appear to be mixing limited for all cases. This result is used to develop a combustion model for a quasi-1-D scramjet combustor code.
\end{abstract}

\section{Nomenclature}

$e_{\mathrm{OH} *}, e_{\mathrm{CH}} \quad$ emission intensity of $\mathrm{OH}^{*}$ or $\mathrm{CH}^{*}$ luminosity per unit volume

$f \quad$ mixture fraction

$H \quad$ test section height in constant area section

$i_{\mathrm{OH} *}, i_{\mathrm{CH}} \quad$ intensity of $\mathrm{OH}^{*}$ or $\mathrm{CH}^{*}$ luminosity signal recorded by the camera per unit area

$I_{O H *}, I_{C H *} \quad$ intensity of $\mathrm{OH}^{*}$ or $\mathrm{CH}^{*}$ luminosity signal recorded by the camera per unit length

$l_{90 \%}$

$M$

$\dot{m}_{\text {cavfuel }}$

$\dot{m}_{\text {totalfuel }}$

$\dot{m}_{f}(y)$

$\phi$

$P_{w}$

$P_{0, i}$

$\dot{q}$

$\dot{Q}$

$T$

$T_{0}$

$T_{w}$

$u$

W flame length based on location where $90 \%$ of the heat release has occurred

Mach number

mass flow rate of cavity pilot fuel

mass flow rate of total fuel (includes cavity and main fuel)

mass flux of fuel through the $y$ - $z$ plane integrated over the width of the test section

overall equivalence ratio ( $\dot{m}_{\text {totalfuel }} /$ stoichiometric $\dot{m}_{\text {totalfuel }}$ )

wall static pressure

air stagnation pressure upstream of the nozzle

heat release rate per unit volume

heat release rate per unit length

static temperature

vitiated air stagnation temperature

wall temperature

axial velocity

test section width

axial location in test section measured from cavity leading edge

vertical location in test section measured from top of cavity

spanwise location in test section measured from test section wall

combustion efficiency

density

scalar dissipation rate

\footnotetext{
* Graduate Student, Department of Aerospace Engineering, AIAA Member

${ }^{\dagger}$ Professor, Department of Aerospace Engineering, AIAA Fellow
} 


\section{Introduction}

The axial distribution of heat release is quite important in dual-mode scramjet combustors since it determines the conditions under which isolator unstart and ram-to-scram transition occurs. For ramjet mode operation this distribution sets the location of the thermal throat, and thus the entire distribution of Mach number, pressure, and other flow quantities in the combustor. ${ }^{1,2}$ Due to its effect on overall engine performance and operability limits, it is important to be able to predict the heat release distribution over the range of operating conditions.

For dual-mode scramjet powered vehicles, there is a strong a coupling between the exterior aerodynamics, the airframe flexibility, and the amount of thrust generated. Thus all of these dynamics must be simulated simultaneously for effective vehicle stability and control. Current full-fidelity modeling is not capable of simulating all structural, thermal, aerodynamic and chemical effects within the time needed for validation of stability and control models. Quasi-one-dimensional models are under development which retain the majority of the dynamics while requiring much less computation time. ${ }^{3}$ Accurately modeling the heat release in the engine requires correctly computing the flow path leading up to the combustor, and the mixing and chemical kinetics within the combustor. Current efforts are concentrated on accurately representing the combustion in the reduced order model. More information is needed about the factors limiting the heat release rate to accurately predict the distribution over a wide range of conditions.

The objective of the current study is to gain a better understanding of the factors controlling the heat release distribution in dual-mode scramjet combustors and how model it effectively. The heat release distribution in a laboratory dual-mode scramjet combustor is evaluated experimentally from images of $\mathrm{OH}^{*}$, $\mathrm{CH}^{*}$, and wall pressure measurements. The experimental results are used to determine the limiting factors for the heat release rate in different regions of the combustor. This information is then used to develop a method for simulating the combustion for use in a quasi-1-dimensional scramjet model. The scramjet engine model is discussed in depth in Ref. 3.

The heat release distribution in dual-mode combustors is expected to be highly dependent on the fuel injection and flameholding configuration. Wall fuel injection with a cavity flame holder is a desirable configuration for dual-mode scramjet combustors due to the low pressure losses and cooling requirements. ${ }^{4-6}$ The cavity recirculation zone provides a long residence time for the fuel and air to mix and burn. The cavity flame provides a source of heat and radicals to ignite and stabilize combustion in the main flow. The main fuel injection may be normal to the air flow to achieve maximum penetration or it may be angled to recover some of the jet momentum. The current study focuses on the heat release distribution from a single, perpendicular wall fuel injector upstream of a wall cavity flameholder.

\section{Facilities and Diagnostics}

\section{A. Experimental Setup and Conditions}

Experiments were performed in the supersonic combustion facility at the University of Michigan. This facility supplies $0.21 \mathrm{O}_{2}$ mole fraction vitiated air with stagnation temperatures $\left(T_{0}\right)$ up $1520 \mathrm{~K}$. The main flow combustion for each run in this study was maintained for 3 seconds following 6 seconds of vitiator operation to partially preheat the walls. The test section is made of stainless steel and is shown in Figure 1. A two dimensional Mach 2.2 nozzle exits into a constant area isolator with a cross section of $25.4 \mathrm{~mm}$ by $38.1 \mathrm{~mm}$. The constant area isolator is followed by a wall cavity flameholder and a 4 degree diverging section. Room temperature gaseous fuel was injected sonically through a single 2.49 mm diameter port located on the test section centerline $44.5 \mathrm{~mm}$ upstream of the cavity leading edge. Pilot fuel was also injected through three ports in the cavity trailing edge. The constant area isolator, sonic wall fuel injection, cavity flameholder, and diverging combustor are features that have been proposed for practical dual-mode scramjet combustors. Additional details on the facility and test section can be found in Ref. 7 .

Data was acquired at the conditions given in Table 1. A previous study in this combustor found two distinct reaction zone structures: cavity stabilized combustion and jet-wake stabilized combustion. ${ }^{7}$ Case $1 \mathrm{H}$ and $1 \mathrm{~B}$ are the baseline cavity stabilized combustion cases for hydrogen fuel, and a blend of $50 \% \mathrm{H}_{2}$, $50 \% \mathrm{C}_{2} \mathrm{H}_{4}$ by mole fuel. Case $2 \mathrm{H}$ and $2 \mathrm{~B}$ are the baseline jet-wake stabilized combustion cases for hydrogen and the blended fuel. The effects of varying the air stagnation temperature and the overall equivalence ratio were examined in data sets $\mathrm{A}$ and B. For all cases, $5 \%$ of the total fuel was injected through the cavity rear wall ports. 


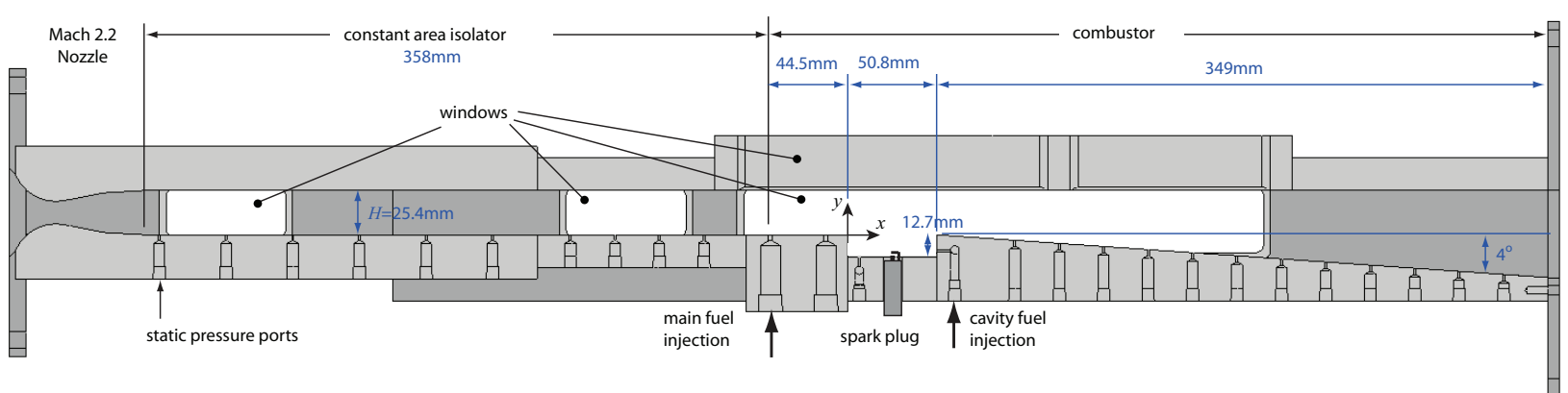

Figure 1. Uninvest of Michigan dual-mode combustor

\begin{tabular}{llllll}
\hline Case & $T_{0}$ & fuel composition & stabilization mode & $\phi_{\text {overall }}$ & $\frac{\dot{m}_{\text {cavfuel }}}{\dot{m}_{\text {totalfuel }}}$ \\
\hline \hline case 1B & $1270 \mathrm{~K}$ & $50 \% \mathrm{H}_{2}, 50 \% \mathrm{C}_{2} \mathrm{H}_{4}$ & cavity & 0.42 & 0.05 \\
case 2B & $1470 \mathrm{~K}$ & $50 \% \mathrm{H}_{2}, 50 \% \mathrm{C}_{2} H_{4}$ & jet-wake & 0.42 & 0.05 \\
case 1H & $1130 \mathrm{~K}$ & $100 \% \mathrm{H}_{2}$ & cavity & 0.27 & 0.05 \\
case 2H & $1370 \mathrm{~K}$ & $100 \% \mathrm{H}_{2}$ & jet-wake & 0.27 & 0.05 \\
set A & $1220 \mathrm{~K}-1520 \mathrm{~K}$ & $100 \% \mathrm{H}_{2}$ & jet-wake & 0.26 & 0.05 \\
set B & $1500 \mathrm{~K}$ & $100 \% \mathrm{H}_{2}$ & jet-wake & $0.23-0.36$ & 0.05 \\
\hline
\end{tabular}

Table 1. Test conditions.

\section{B. $\mathrm{OH}^{*}$ and $\mathrm{CH}^{*}$ imaging}

1. $\mathrm{OH}^{*}$ and $\mathrm{CH}^{*}$ as markers of heat release rate

It is difficult to directly measure the heat release rate in any combustion environment. Experimentally then, the heat release rate is inferred from the measurement of other flow quantities which have some correlation to it. Chemiluminescence is often used as a marker of the heat release rate in flames. ${ }^{8-11}$ The chemiluminescence in hydrocarbon flames comes primarily from $\mathrm{OH}^{*}, \mathrm{CH}^{*}, \mathrm{C}_{2}{ }^{*}$, and $\mathrm{CO}_{2}{ }^{*}{ }^{12} \mathrm{CH}^{*}$ and $\mathrm{C}_{2} *$ are confined to much thinner layers than $\mathrm{OH}^{*}$ and $\mathrm{CO}_{2}{ }^{*},{ }^{13}$ and thus may be better markers of the location of heat release for scramjet combustor conditions. Evidence that the heat release rate is proportional to the chemiluminescence first came from Price $^{8}$ who showed that the sound pressure generated by turbulent flames was directly proportional to the rms of the chemiluminescence signal. Heat release has also been shown to be proportional to the luminescence of $\mathrm{OH}^{*}, \mathrm{CH}^{*}$, and $\mathrm{CO}_{2}{ }^{*}$ individually for many cases. ${ }^{10}$ However the luminosity from $\mathrm{OH}^{*}$ and $\mathrm{CH}^{*}$ can be dependent on the local equivalence ratio and strain rate as well. ${ }^{9,10}$ Therefore care must be taken when interpreting images of $\mathrm{OH}^{*}$ and $\mathrm{CH}^{*}$ for cases where local conditions at the flame surface can vary significantly across the image (as in the case of thermally choked ramjet mode combustion).

\section{Image acquisition}

The luminosity from $\mathrm{OH}^{*}$ and $\mathrm{CH}^{*}$ was imaged using $\pm 10 \mathrm{~nm}$ bandwidth interference filters centered at 310 $\mathrm{nm}$ and $430 \mathrm{~nm}$ respectively. Images of the unfiltered luminosity are not reported due to significant radiation from the hot cavity rear wall which saturated the camera. Two Andor Istar intensified cameras were used to collect the $\mathrm{OH}^{*}$ and $\mathrm{CH}^{*}$ luminosity images simultaneously from opposite sides of the test section during each run. The $\mathrm{OH}^{*}$ camera was fitted with a $\mathrm{f} 4.5 / 105 \mathrm{~mm}$ UV Nikkor lens while the $\mathrm{CH}^{*}$ camera used a f4.0/50 mm Nikkor lens. Both cameras imaged an area of approximately $310 \times 42 \mathrm{~mm}$ on a $1024 \times 140$ pixel array. This array was binned $2 \times 2$ to allow $8 \mathrm{~Hz}$ operation of the cameras due to the limited main fuel run times. Each run condition was repeated until 50-75 luminosity images were obtained. 


\section{1-D signal from average images}

It was useful to convert the $\mathrm{CH}^{*}$ and $\mathrm{OH}^{*}$ images into a one-dimensional signal for further analysis. It can be shown that these 1-D measured intensities of $\mathrm{CH}^{*}$ and $\mathrm{OH}^{*}\left(I_{C H *}(x)\right.$ and $\left.I_{O H *}(x)\right)$ are proportional to the local heat release rate per unit length $(\dot{Q}(x))$ if the local heat release rate per unit volume is proportional to the intensity of $\mathrm{CH}^{*}$ (or $\mathrm{OH}^{*}$ ) emissions per unit volume. Let $\dot{q}(x, y, z)$ the be the local heat release per unit volume and $e_{\mathrm{OH}}(x, y, z)$ be the intensity of $\mathrm{OH}^{*}$ chemiluminescence per unit volume. The axial distribution of the $\mathrm{OH}^{*}$ luminosity per unit length $E_{O H *}(x)$ is then found by integrating $e$ over the $y-z$ plane for each $x$ as shown in Fig. 2.

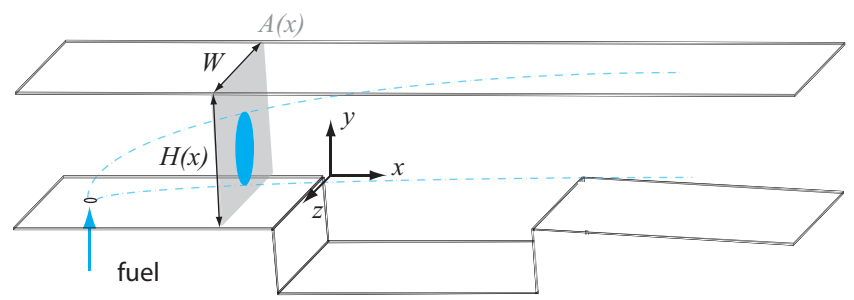

Figure 2. Integration of heat release and luminosity signal.

The intensity of the $\mathrm{OH}^{*}$ signal measured by the camera $\left(i_{\mathrm{OH} *}(x, y)\right)$ is proportional to $e_{\mathrm{OH}}$ integrated in the z direction as shown in Eq. 1. The constant of proportionality is related to the geometry and efficiency of the collection optics and camera.

$$
i_{O H *}(x, y) \propto \int_{0}^{W} e_{O H *}(x, y, z) d z
$$

Then the measured 1-D $\mathrm{OH}^{*}$ (or similarly $\mathrm{CH}^{*}$ ) signal is given by 2 .

$$
I_{O H *}(x)=\int_{0}^{H(x)} i_{O H *}(x, y) d y
$$

Similarly, if the local volumetric heat release rate $q(x, y, z)$ is proportional to the local intensity of the chemiluminescence emissions $e_{O H *}$ and $e_{C H *}$, then the heat release rate per unit length $\dot{Q}(x)$ is proportional to the 1-D signal of $\mathrm{OH}^{*}$ (or $\mathrm{CH}^{*}$ ) given by Eq. 2.

$$
\dot{Q}(x) \propto I_{O H *}(x) \propto I_{C H *}(x)
$$

\section{Wall pressure measurements and a 1-D data analysis model}

Wall pressure measurements are often used to study the flow in dual-mode combustors because they are nonintrusive and generally easy to obtain. Wall static pressure ports were located throughout the combustor and isolator with spacing of 25.4-38.1 mm. During each run, pressure data was recorded at eight locations at $40 \mathrm{~Hz}$. The monitoring locations were changed between runs to obtain the average pressure at 30 locations in the test section.

The wall pressure measurements were used in conjunction with a one-dimensional model to obtain the average flow conditions and heat release throughout the combustion and isolator. The model solves the onedimensional mass, momentum, and energy conservation equations (with area change). The wall pressure data is input into the model to solve for the unknown percentage of reacted fuel at each axial location in the

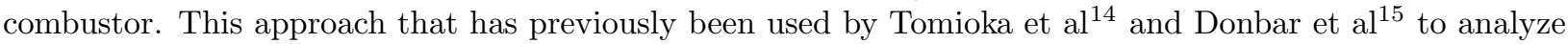
dual-mode scramjet combustors from wall pressure data.

For the current study a MATLAB code was created to solve the one-dimensional conservation equations with area change. The isolator entrance conditions, combustor area distribution, and wall pressure distribution were used as inputs. A continuous function for $P(x)$ was needed to solve the differential conservation equations. This function was obtained from the experimental data at discrete points by creating a spline fit for each case. These spline fits are shown along with the experimental data in Figs. 3] and 4. A single

$$
4 \text { of } 19
$$


step chemistry was assumed that included only the major species of $\mathrm{H}_{2}, \mathrm{C}_{2} \mathrm{H}_{4}, \mathrm{O}_{2}, \mathrm{~N}_{2}, \mathrm{H}_{2} \mathrm{O}$, and $\mathrm{CO}_{2}$. This allowed all species concentrations to be written as algebraic functions of the single variable combustion efficiency $\left(\eta_{c}(x)\right)$, which was solved for by the model. Combustion efficiency is a reaction progress variable that is defined as:

$$
\eta_{c}(x)=\frac{\dot{m}_{\text {fuel, burned }}(x)}{\dot{m}_{\text {fuel }, \text { injected }}}
$$

Skin friction and heat transfer to the wall were calculated using the van Driest method and Reynolds analogy.

\section{Pressure and 1-D data Analysis Model Results}

Detailed wall pressure distributions were obtained for cases $1 \mathrm{H}, 2 \mathrm{H}, 1 \mathrm{~B}$, and $2 \mathrm{~B}$ and are shown in Figs. 3 and 4. For both fuel types, the pre-combustion shock train has a greater length and pressure rise for jet-wake stabilized combustion (cases $2 \mathrm{~B}$ and $2 \mathrm{H}$ ) than for cavity stabilized combustion (cases $1 \mathrm{~B}$ and $1 \mathrm{H}$ ). In all cases, the pressure begins to decrease after the start of the reaction zone. There is a sharp decrease in pressure near the cavity trailing edge (start of the diverging section) that is more pronounced for jetwake stabilized combustion than cavity stabilized combustion. Downstream of the cavity trailing edge, the pressure is higher for cavity stabilized combustion than jet-wake stabilized combustion.

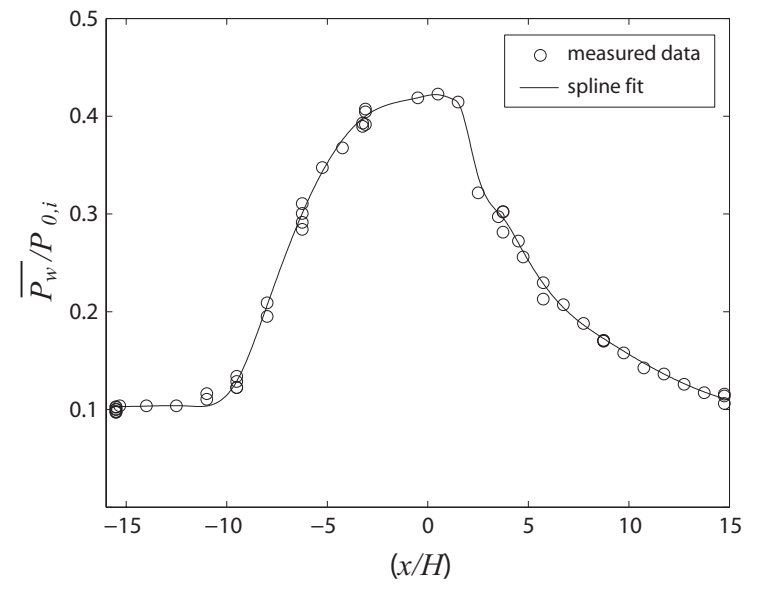

(a) Case 1B.

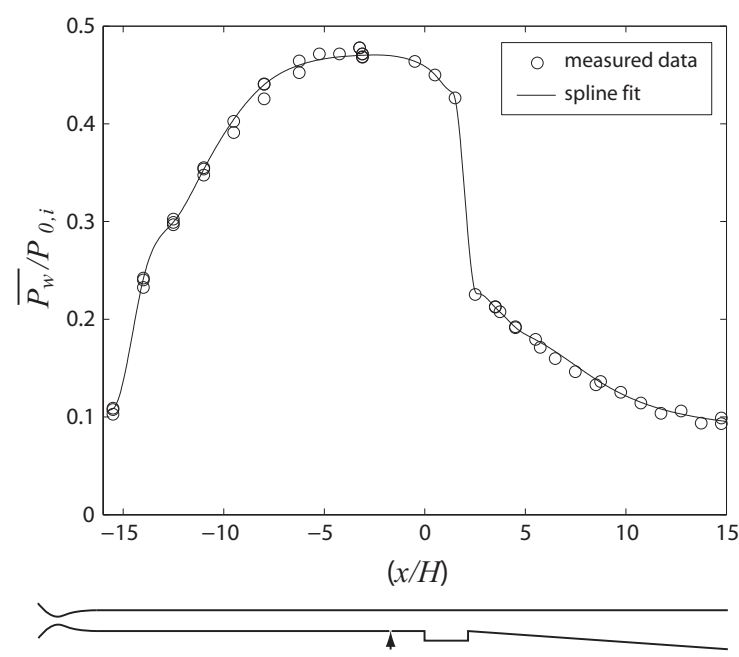

(b) Case 2B.

Figure 3. Average wall pressure distribution for case $1 \mathrm{~B}$ and 2B with spline fit used in model. Multiple data points at same location are averages from different runs.

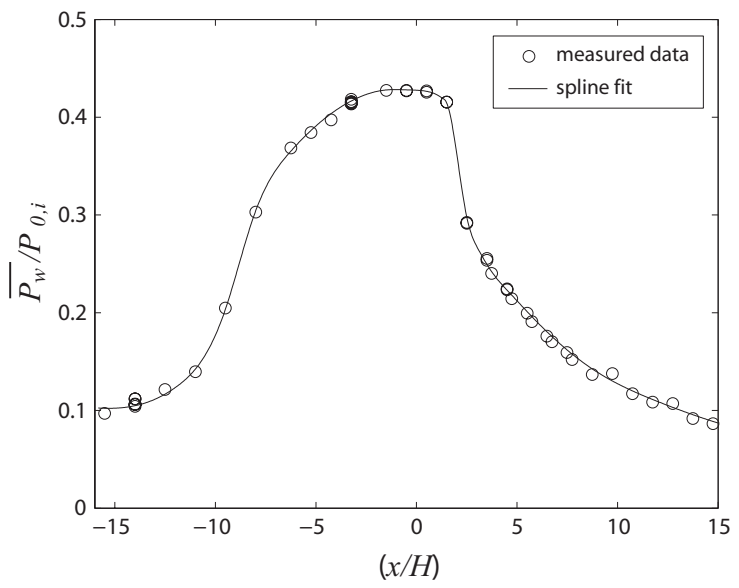

(a) Case $1 \mathrm{H}$.

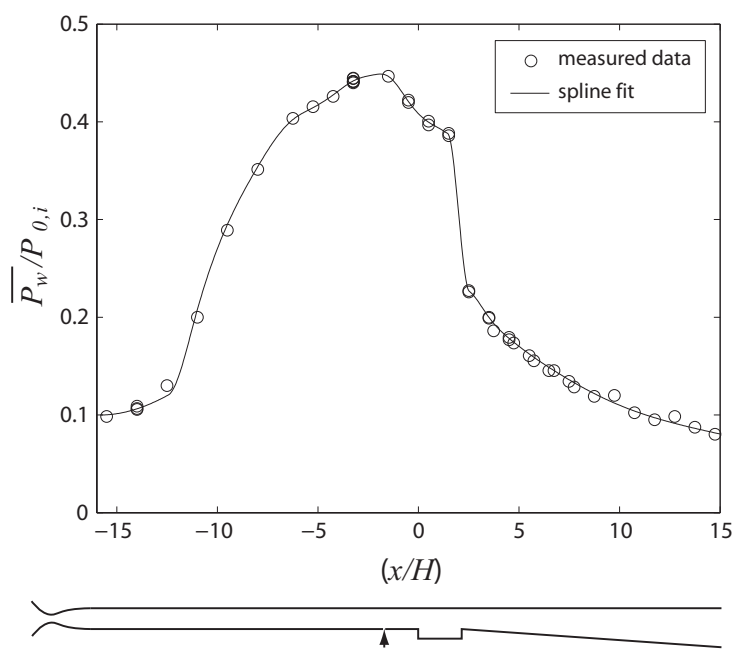

(b) Case $2 \mathrm{H}$.

Figure 4. Average wall pressure distribution for case $1 \mathrm{H}$ and $2 \mathrm{H}$ with spline fit used in model. Multiple data points at same location are averages from different runs 
The biggest source of uncertainty in the one-dimensional data analysis model comes from the heat transfer to the wall. There is no data available for the wall temperatures in the combustor. Due to the relatively short runs times, the combustor is not in thermal equilibrium, and the heat transfer is expected to be significant. The overall combustion efficiency calculated by the model is quite sensitive to the heat transfer to the wall the wall. Figures 5.8 show the calculated combustion efficiency for cases 1B-2H for assumed constant wall temperatures of $T_{0}-100 K, T_{0}$, and $T_{0}+100 \mathrm{~K}$. It can be seen that the overall combustion efficiency varies significantly over this range of wall temperatures, and thus cannot be reliably calculated by the model with the available information.

The axial derivative of the combustion efficiency $\left(d \eta_{c} / d x\right)$ is a measure of the heat release rate per unit length. This quantity is also shown in Figs. 5.8 for cases 1B-2H. It can be seen that this curve is shifted up or down for varying wall temperatures, but the shape remains fixed. There are some general trends from these curves that are consistent with the $\mathrm{OH}^{*}$ and $\mathrm{CH}^{*}$ distributions discussed in Sec. IV, The heat release generally peaks over the cavity and decreases at the trailing edge. Jet-wake stabilized combustion has a more highly peaked heat release distribution than cavity stabilized combustion. The heat release distribution curves shown in 5.8 are much less smooth than those found from the $\mathrm{CH}^{*}$ and $\mathrm{OH}^{*}$ in Sec. IV though. As a derivative quantity, $d \eta_{c} / d x$ is sensitive to the derivative of the pressure distribution $(d P(x) / d x)$. Due to the discrete nature of the wall pressure data, this quantity is not known accurately in some areas. This is particularly true in regions where the pressure changes quickly, such as near the cavity trailing edge. Additionally, the 1-D model cannot properly account for the changes at discrete waves. Both these issues lead to artifacts such as negative values of $d \eta_{c} / d x$ near the cavity trailing edge in Figs. 6 and 8 .

The distributions of Mach number, velocity, density, and static temperature predicted by the 1-D data analysis model are shown in Figures 9 and 10 for cases 1B-2H. These distributions are virtually independent of the heat transfer to the wall. The calculated local rate of heat release offsets any change in heat transfer to the wall. The temperature field is nearly independent of the wall temperature (except for very minor differences caused by changes in the average molecular weight). Thus the distribution of these variables can be used with a degree of confidence.

In all cases, the thermal throat $(\mathrm{M}=1$ location) is located near the beginning of the diverging section, just behind the cavity trailing edge. For jet wake stabilized combustion (case $2 \mathrm{~B}$, and $2 \mathrm{H}$ ), the thermal throat is located further upstream than for cavity stabilized combustion (case 1B and $1 \mathrm{H}$ ). The Mach number, velocity, and density change more abruptly at the choked point for jet-wake stabilized combustion. The static temperature is virtually unchanged through the combustion region for the jet-wake stabilized cases, and rises slightly for the cavity stabilized cases. The increase in stagnation temperature from the reaction is mostly offset by the increase in Mach number (which decreases $T / T_{0}$ ). It should be noted that the variables shown in Figs. 9] and 10 are mixture averaged 1-D results, and are not necessarily representative of any local conditions. The step change in static temperature and density observed near the injection location is due to the instantaneous addition and mixing of room temperature fuel in the model. The results shown in Figs. 9 and 10 are useful for interpreting the $\mathrm{OH}^{*}$ and $\mathrm{CH}^{*}$ results in Sec. IV.

\section{IV. $\mathrm{OH}^{*}$ and $\mathrm{CH}^{*}$ Distributions}

\section{A. Comparison of $\mathrm{OH}^{*}$ and $\mathrm{CH}^{*}$ Results}

The mean $\mathrm{CH}^{*}$ and $\mathrm{OH}^{*}$ images for cases $1 \mathrm{~B}$ and $2 \mathrm{~B}$ are shown in Figs. 11 and 12. There are no major differences in the shape or size of the reaction zone as indicated by the $\mathrm{CH}^{*}$ and $\mathrm{OH}^{*}$. The 1-D signal obtained from these images is shown in Fig. 14. The signals are normalized by the area under the curve, which is proportional to the total heat release. There is relatively little difference between the distribution of $\mathrm{OH}^{*}$ and $\mathrm{CH}^{*}$ in these figures. As discussed in Sec. 1, $\mathrm{CH}$ exists only in regions of local heat release, and thus is likely to be a good marker of the heat release distribution in this very high speed flow. OH can persist downstream in the hot products, and thus may give a distorted picture of the heat release distribution. Figure 14 shows relatively minor differences between the distribution of $\mathrm{OH}^{*}$ and $\mathrm{CH}^{*}$ for case $1 \mathrm{~B}$ and $2 \mathrm{~B}$. Thus $\mathrm{OH}^{*}$ is likely a reasonably marker of the heat release distribution under these conditions. The small difference between the $\mathrm{OH}^{*}$ and $\mathrm{CH}^{*}$ signals near the rear of the combustor in Fig. 14(a) is probably due to the contribution of $\mathrm{OH}^{*}$ in the hot products. 


\section{B. Cavity Stabilized Combustion}

The mean $\mathrm{OH}^{*}$ images for cases $1 \mathrm{~B}$ and $1 \mathrm{H}$ are shown in Figs. 12(a) and 13(a). As discussed in Ref. 7 , the cavity stabilized reaction zone begins at the upstream edge of the cavity shear layer and spreads into the premixed reactants at an approximately constant angle (initially). The spreading angle is set by the flame speed and the flow speed. At downstream locations, the spreading angle decreases as the flow velocity increases (shown in Figs. 9 and 10 ).

The 1-D OH* signals are shown in Fig. 15, For both cavity stabilized cases, the $\mathrm{OH}^{*}$ increases approximately linearly in the $x$ direction over the cavity. As with the 1-D model results, the decrease in $\mathrm{OH}^{*}$ starts near the cavity trailing edge. The decrease in the heat release indicated by the $\mathrm{OH}^{*}$ signal at this location is much less abrupt than that indicated by the model. Near the rear of the window the $\mathrm{OH}^{*}$ emissions from the cavity stabilized mode approaches that of the jet wake stabilized mode. For both cavity stabilized modes, there is a trend of consistent decreasing $\mathrm{OH}^{*}$ signal behind the cavity trailing edge. In addition to the this consistent trend, there is locally decreased $\mathrm{OH}^{*}$ signal for $2 \lesssim x / H \lesssim 3$.

\section{Jet-Wake Stabilized Combustion}

The mean $\mathrm{OH}^{*}$ images for cases $2 \mathrm{~B}$ and $2 \mathrm{H}$ are shown in Figs. $12(\mathrm{~b})$ and $13(\mathrm{~b})$. The 1-D $\mathrm{OH}^{*}$ signals are shown in Fig. 15. As seen in the flame luminosity images in Ref. 7, the jet-wake stabilized reaction zones begin upstream of the cavity stabilized ones. At the start of the reaction zone, the $\mathrm{OH}^{*}$ increases quickly to the peak value. The reaction zone leading edge and the peak $\mathrm{OH}^{*}$ occur farther downstream for case $2 \mathrm{~B}$ than case $2 \mathrm{H}$. Behind the peak $\mathrm{OH}^{*}$ location, the signal decreases gradually until the cavity trailing edge, where it decreases very sharply. Behind the cavity trailing edge, the $\mathrm{OH}^{*}$ decreases slowly and does not reach zero by the end of the window.

\section{Effect of varying $T_{0}$}

Figure 16 shows the mean $\mathrm{OH}^{*}$ images for data set A conditions. For these cases, $\phi$ remains fixed and $T_{0}$ is varied from $1220 \mathrm{~K}$ to $1520 \mathrm{~K}$ ). It can be seen that the lower reaction zone leading edge appears to be attached to the fuel injection jet for all temperatures. The upper side of the reaction zone leading edge moves downstream as $T_{0}$ decreases. (This is different than the behavior observed during the flame luminosity imaging of Ref. 7, where the entire reaction zone leading edge moved with $T_{0}$. This hysteresis in the stabilization location is most likely due to the combustor wall temperature. Changes in the order and cooling time between runs led to presumably higher wall temperatures for set A than for the cases in Ref. 7).

The 1-D $\mathrm{OH}^{*}$ signals for set A are shown in Fig. 18(a). The basic shape of the $\mathrm{OH}^{*}$ distribution is the same as that seen for case $2 \mathrm{H}$. The reaction zone starts in the same location for all cases due to the attached stabilization location. However the $\mathrm{OH}^{*}$ signal rises more slowly for the lower $T_{0}$ cases, causing the peak $\mathrm{OH}^{*}$ value to occur further downstream. Near the cavity trailing edge, all the $\mathrm{OH}^{*}$ signals drop sharply. Further downstream the signals for all cases are virtually identical. The highest temperature case does have slightly lower $\mathrm{OH}^{*}$ signal behind the cavity trailing edge.

The decrease in $\mathrm{OH}^{*}$ signal near the cavity trailing edge clearly is a prominent feature of the jet-wake stabilized combustion. Part of this decrease is due to the abrupt end of any reaction in the cavity. It is useful to separate this effect from the decrease in main flow reaction rate. Figure 18(b) shows the 1-D OH* data for set A with the contribution from the cavity reaction excluded. In this figure it can be seen that the $\mathrm{OH}^{*}$ is already decreasing quickly before the cavity trailing edge, but there is still a pronounced decrease at this location.

\section{Effect of varying $\phi$}

Figure 16 shows the mean $\mathrm{OH}^{*}$ images for data set $\mathrm{B}$ conditions. For these cases $T_{0}$ is fixed and $\phi$ is varied from 0.23 to 0.36 . The shape of the reaction zone has the same general appearance in all cases. Figure 19 shows the 1-D OH* signals for each of these cases with and without the cavity reaction included. In the upstream region up to the peak $\mathrm{OH}^{*}$ value, the profiles are virtually identical for all cases in set $\mathrm{B}$. Downstream of the peak $\mathrm{OH}^{*}$ location, the $\mathrm{OH}^{*}$ signal decreases more quickly for the lower $\phi$ cases. Near the cavity trailing edge, the $\mathrm{OH}^{*}$ signal drops sharply for all cases. 
The $\mathrm{OH}^{*}$ signals in Fig. 19 were not normalized by the area under the curve as in the previous $1-\mathrm{D} \mathrm{OH}^{*}$ figures. The area under the $\mathrm{OH}^{*}$ curve is proportional to the total heat release rate, assuming that the local heat release rate per unit volume is proportional to the intensity of $\mathrm{OH}^{*}$ emissions per unit volume. The accuracy of this assumption can be evaluated by examining the change in area under the $\mathrm{OH}^{*}$ curves for set $\mathrm{B}$. Because the end of the reaction zone occurs past the end of the window, the $\mathrm{OH}^{*}$ data for each case was extrapolated until it reached zero. A linear regression fit was used for this extrapolation since the $\mathrm{OH}^{*}$ signal decreased roughly linearly behind the cavity trailing edge. The results are shown in Fig. 20. The area under these curves is plotted as function of $\phi$ in Fig. 21 along with a linear best fit line that passes through the origin. It can be seen that the area under the $\mathrm{OH}^{*}$ curves increases linearly with $\phi$. Thus the assumption of the proportionality of the $\mathrm{OH}^{*}$ emissions to heat release appears to be relatively good for the current conditions.

The extrapolated $\mathrm{OH}^{*}$ curves in Fig. 20 also can be used to obtain the flame length as a function of $\phi$, which is plotted in Fig. 22. The measure of flame length used in this figure $\left(l_{90 \%}\right)$ is the distance between the fuel injection and the location the area under the extrapolated $\mathrm{OH}^{*}$ curve is $90 \%$ of the total area. Given the previous assumptions, this is equal to the length where $90 \%$ of the heat release has occurred. This measure of the flame length can be obtained more accurately from the current data than the total length of the flame (where $100 \%$ of the heat release has occurred), because it is less dependent on the details of the data extrapolation.

\section{Factors Controlling the Heat Release}

\section{A. Jet-Wake Stabilized Combustion}

The heat release distribution for jet-wake stabilized combustion is mostly consistent with the lifted diffusion flame description proposed in Ref. 7. The initial peak in $\mathrm{OH}^{*}$ (or $\mathrm{CH}^{*}$ ) signal corresponds to the premixed flame base where the fuel that has premixed with air in the lift-off distance is consumed. After the end of the premixed flame base, the combustion is mixing limited. These regions are illustrated in Fig. 23. Recent PLIF imaging in the combustor suggests a rich premixed flame cone exists inside flame base along the jet-perimeter.

The changes observed when $T_{0}$ and $\phi$ were varied are consistent with this description. Changes in $T_{0}$ affect the stabilization and spreading of the premixed flame base, but have little effect on the mixing field. Therefore the upstream part of the heat release distribution is effected by changes in $T_{0}$ while the mixing limited downstream region is not. This result is not consistent with the downstream reaction being finite rate kinetics limited. The premixed flame base consists of a ring around the perimeter of the fuel jet and an inner, rich cone. As $T_{0}$ is decreased in data set $\mathrm{A}$, the premixed flame spreading from the stabilization point around the jet perimeter slows. This moves the upper edge of the flame base downstream. The downstream end of the premixed flame region occurs near $x / H=1.5$ for the lowest temperature case in Fig. 18. As $\phi$ is varied, the overall flame length changes due to changes in the stoichiometric mixing length. Both of these trends are consistent with the physical concept of a lifted diffusion flame.

The sharp decrease in $\mathrm{OH}^{*}$ signal near the cavity trailing edge in all cases also is explained by the above description. As seen in Figs. 9] and 10, the thermal throat is located shortly downstream of the cavity trailing edge in all cases. Across this throat there is a very large increase in velocity, a large decrease density, and a modest decrease in static temperature for the jet-wake stabilized combustion cases. In a diffusion flame a decrease in reaction rate would be caused by a decrease in the fuel-air mixing rate. An estimate of the change in mixing rate can be obtained from the similarity solution for co-flowing jets since the fuel jet is turned to be nearly parallel to the air stream by the cavity trailing edge. The rate of fuel-air mixing then can be estimated to be proportional to the mass entrainment rate of a co-flowing jet. The mass flow rate contained in a co-flowing jet is given by Han and Mungal ${ }^{16}$ as:

$$
\dot{m}(x)=C_{1} \rho_{c} u_{c} \delta^{2}+C_{2} \rho_{c} u_{\infty} \delta^{2}
$$

In the far field, the wake similarity solution applies for which $u_{c}$ and $\delta$ are given by: 7 .

$$
\begin{aligned}
\frac{u_{c}}{u_{\infty}} & =\left(C_{u}\right)_{w}\left(\frac{x}{\theta}\right)^{-2 / 3} \\
\frac{\delta}{\theta} & =\left(C_{\delta}\right)_{w}\left(\frac{x}{\theta}\right)^{1 / 3}
\end{aligned}
$$

$$
8 \text { of } 19
$$




$$
\theta^{2}=\frac{J_{0}}{\rho_{\infty} U_{\infty}^{2} \pi}
$$

$J_{0}$ is the initial momentum mass flux of the co-flowing jet, or drag in the case of the case of the transverse jet. Making the assumption that $u_{c}=u_{\infty}$ in the far field yields the following expression for the mass flow rate contained in the jet as a function of $x$.

$$
\dot{m}(x)=C_{3} \frac{J_{0}}{u_{\infty}}+C_{4} \rho_{\infty}^{1 / 3} \frac{J_{0}^{2 / 3}}{u_{\infty}^{1 / 3}} x^{1 / 3}
$$

The entrainment rate is obtained by differentiating the mass flow rate with respect to $x$.

$$
\frac{d \dot{m}}{d x} \propto C_{5}\left(\frac{\rho_{\infty}}{u_{\infty}}\right)^{1 / 3} J_{0}^{2 / 3} x^{-1 / 3}
$$

Hasselbrink and Mungal ${ }^{17,18}$ found the same scaling of entrainment rate with respect to $\rho_{\infty}$ and $u_{\infty}$ for the far field of a jet in crossflow.

Thus for a fixed jet drag and location, Eq. 10 indicates that the mixing rate will decrease as $u_{\infty}$ increases or $\rho_{\infty}$ decreases. Therefore the heat release rate for a diffusion flame would be expected to decrease quickly as the gas passes through the thermal throat. We can attempt to account for this decreased mixing rate by multiplying $I_{O H *}$ by $u^{1 / 3} / \rho^{1 / 3} \cdot u(x)$ and $\rho(x)$ are obtained from the 1-D data analysis model of Sec. III. Two of these modified $\mathrm{OH}^{*}$ signals are shown in Fig. 24. It can been seen that this mixing correction factor reduces the decrease in signal that is seen at the rear edge of the cavity, but does not eliminate it. The correction is based on several approximations that do not apply perfectly to the actual combustor flowfield however.

\section{B. Cavity Stabilized Combustion}

The heat release distribution of the cavity stabilized combustion mode is consistent with the premixed flame description from Ref. 7. A flame sheet spreading from the cavity leading edge consumes the premixed fuel-air in the jet-wake from the bottom up. The heat release rate initially increases in the $\mathrm{x}$-direction due to the vertical distribution of fuel in the jet-wake. $\mathrm{CFD}++$ was used to obtain an example of this fuel distribution for case $1 \mathrm{H}$ conditions. The chemistry was turned off to obtain the non-reacting solution. The fuel concentration in the cross-section of the jet-wake at $x / H=1.0$ from this solution is shown in Fig. 25. The mass flow rate of fuel per unit height through this plane $\left(\dot{m}_{f}(y)\right)$ is also shown. $\dot{m}_{f}(y)$ was calculated by integrating the fuel mass flux through the plane over the width ( $z$ direction) of the combustor. A flame sheet spreading in the $y$ direction into this jet would be expected to have an increasing heat release rate with $y$ for the lower half of the jet. The observed flame sheet increases in $y$ for increasing $x$. Thus initial the increasing heat release rate for increasing $x$ is expected.

The heat release rate eventually decreases in the $x$-direction for two reasons. Once the flame sheet reaches the upper half of the jet shown in Fig. 25, the fuel consumption rate of the flame sheet will decrease with increasing $y$ (and thus increasing $x$ ) due to the decreasing $\dot{m}_{f}(y)$. Secondly, the static temperature of the reactants decreases through the thermal throat as the Mach number increases. The temperature change causes a decrease in the flame speed and thus the flame spreading angle. This explains the drop in heat release rate seen behind the cavity trailing edge in for both cases in Fig. 15. For case $1 \mathrm{H}$ the spreading angle is relatively high and the flame sheet appears to reach the center of the fuel plume (on average) before the thermal throat. This explains the slow decrease in heat release rate with $x$ seen a bit upstream of the cavity trailing edge in Fig. 15(b). For case 1B the spreading angle is significantly lower. Therefore the heat release rate increases with $x$ until the sudden change at the thermal throat as seen in Fig. 15(a). The effect of the flame sheet reaching the upper part of the fuel jet is delayed until well downstream.

In the far downstream region, the cavity stabilized reaction most likely becomes mixing limited. The center of the premixed flame sheet starts out rich, as suggested by recent PLIF imaging. Thus there will be unburned fuel that passes through the flame sheet and reacts after mixing with air downstream. The mixing field is not expected to change greatly between the two combustion modes, so the jet wake stabilized results can be used as measure of the mixing limited heat release downstream. The cavity and jet-wake stabilized $\mathrm{OH}^{*}$ and $\mathrm{CH}^{*}$ distributions approach the same values for $x / H \gtrsim 6$. This is likely the region where the flame spreading limited reaction transitions to a mixing limited one.

$$
9 \text { of } 19
$$




\section{Modeling Approaches}

The MASIV code is a quasi-one-dimensional code currently under development which predicts the performance of a dual-mode scramjet engine. ${ }^{3}$ In this model a set of conservation equations is integrated in the axial direction, giving the evolution of thermodynamic quantities and, hence, thrust. Critical to this model is the method of accounting for the enthalpy addition from combustion. The first approach to modeling this enthalpy addition assumed a well mixed, finite rate chemistry limited reaction. ${ }^{19}$ However, the experimental results suggest that under the ramjet mode conditions studied, the fuel actually burns in premixed and diffusion flames. For the jet-wake stabilized cases, it is assumed that the chemistry is sufficiently fast at the flame surface that the combustion downstream of the base is mixing limited, rather than kinetics limited.

To improve prediction of the heat release distribution in the MASIV code, a new enthalpy addition model is being developed. To simulate the mixing limited combustion, an assumed flamelet method is used. In order to generate a flame brush, the jet mixing law given by Hasselbrink and Mungal ${ }^{18}$ is used to paint the entire 3-dimensional duct region with a mean mixture fraction, $\tilde{f}$ (a function of the jet momentum ratio), and mixture fraction fluctuation, $f^{\prime}$ (a function of the rate of change of mean mixture fraction). Finally, the strain rate of the fluid is computed in order to find the scalar dissipation rate, $\chi$. A counter flow stabilized flame is used to generate a lookup table, giving species mass fractions as a function of $\tilde{f}, s=\frac{\tilde{f}^{\prime 2}}{\tilde{f}(1-\tilde{f})}$ and $\chi$, for each location in the profile. The species mass fractions are then integrated across the plane normal to the main flow direction, resulting in a 1-dimensional mass fraction profile for each species. The species mass fractions are then used to calculate the 1-dimensional enthalpy of formation distribution in the combustor. Details of this model are given in Ref. 3 .

\section{Conclusions}

The heat release distribution in a dual-mode scramjet combustor has been estimated using the luminosity from $\mathrm{CH}^{*}$ and $\mathrm{OH}^{*}$ over a range of $\phi$ and $T_{0}$. The luminosity shows a more even distribution of heat release for cavity stabilized combustion than jet-wake stabilized combustion. Analysis of the pressure distribution using a 1-D model confirms this trend.

The cavity stabilized results are consistent with the theory of a premixed flame spreading controlled reaction. The heat release rate begins to decrease after the majority of the fuel jet has been consumed, or the local flame speed decreases due to a drop in static temperature of the reactants through the thermal throat.

The jet wake stabilized combustion is consistent with a lifted jet flame description (premixed flame base with diffusion flame downstream). The peak in heat release seen near the reaction zone leading edge corresponds to the consumption of the fuel that has mixed during the lift-off distance in the premixed flame base. The variation of $T_{0}$ and $\phi$ results are consistent with mixing limited reaction downstream, and inconsistent with finite rate kinetics limited reaction. A sharp drop in heat release is seen in the region of the thermal throat for all cases. This is most likely due to the decreased mixing rate which occurs due to the sudden increase in velocity and decrease in density.

The previous method of simulating the combustion in a 1-D model as being purely finite rate kinetics limited has been shown to be inappropriate for the low $T_{0}$ conditions studied. A new modeling approach is being developed which treats the combustion as a mixing limited diffusion flame. This is expected to more accurately represent the heat release distribution. 


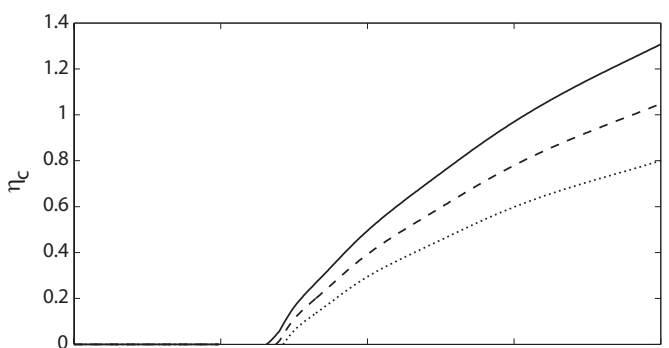

(a)

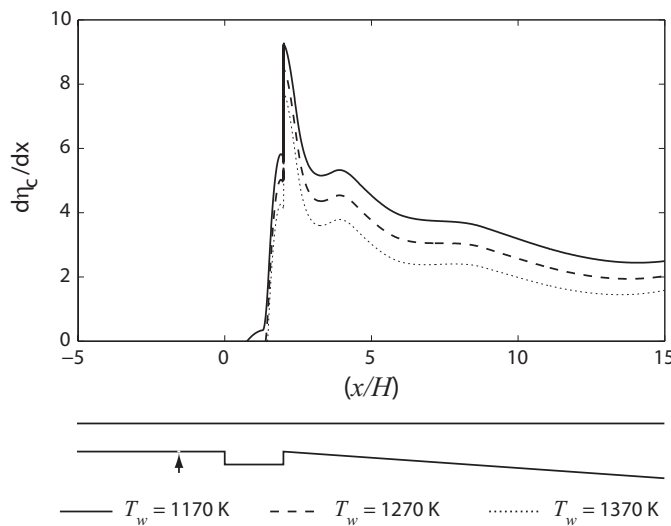

Figure 5. Case 1B distribution of combustion efficiency and its axial derivative calculated by the 1-D data analysis model (from the measured wall pressure) with different assumed (constant) wall temperatures.

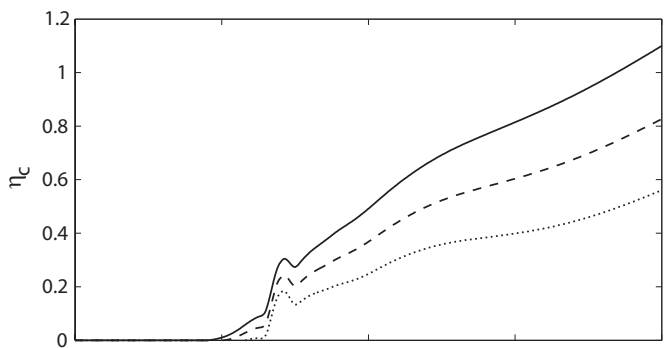

(a)

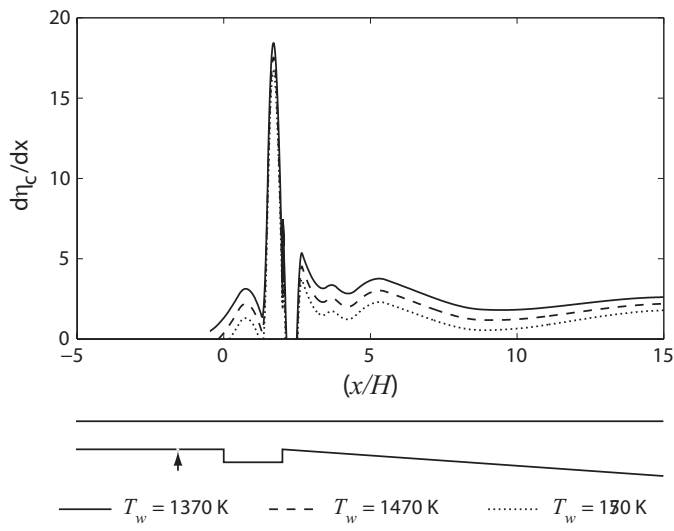

(b)

Figure 6. Case 2B distribution of combustion efficiency and its axial derivative calculated by the 1-D data analysis model (from the measured wall pressure) with different assumed (constant) wall temperatures.

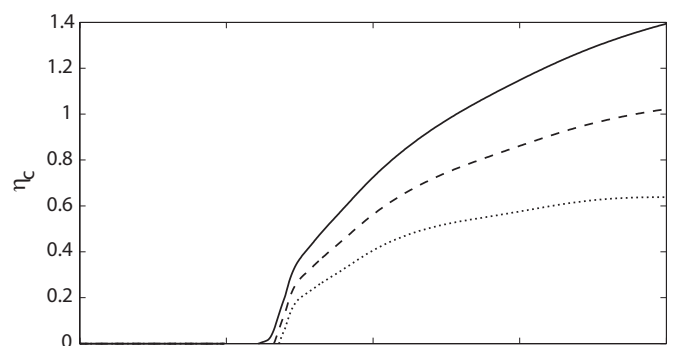

(a)

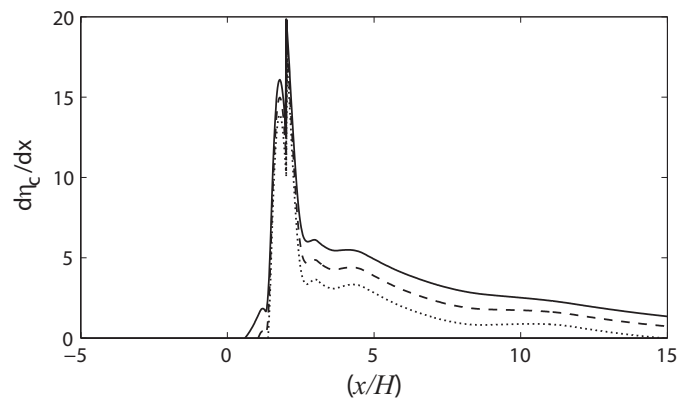

(b)

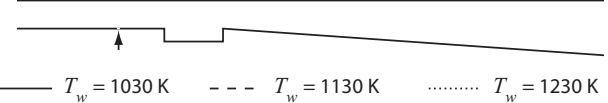

Figure 7. Case 1H distribution of combustion efficiency and its axial derivative calculated by the 1-D data analysis model (from the measured wall pressure) with different assumed (constant) wall temperatures.

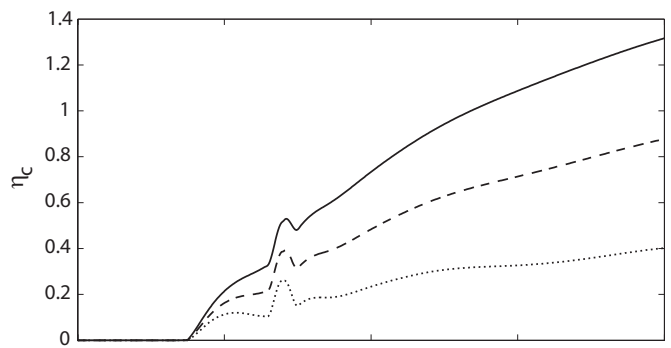

(a)

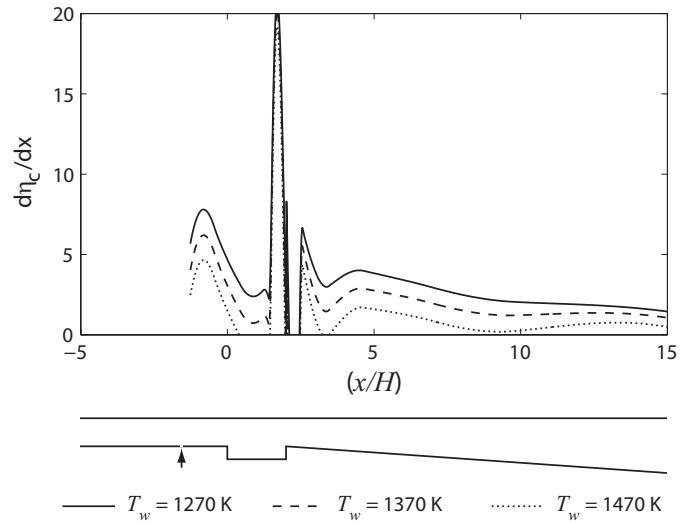

(b)

Figure 8. Case $2 \mathrm{H}$ distribution of combustion efficiency and its axial derivative calculated by the 1-D data analysis model (from the measured wall pressure) with different assumed (constant) wall temperatures. 


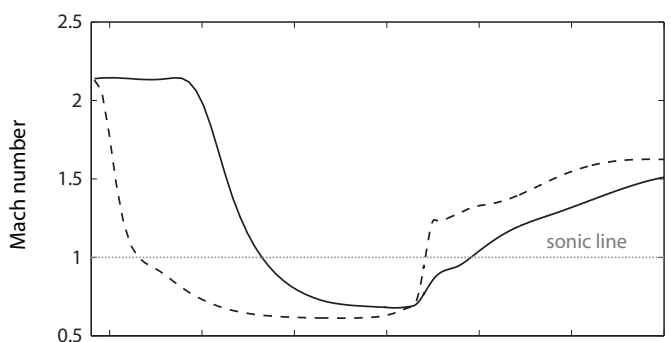

(a)

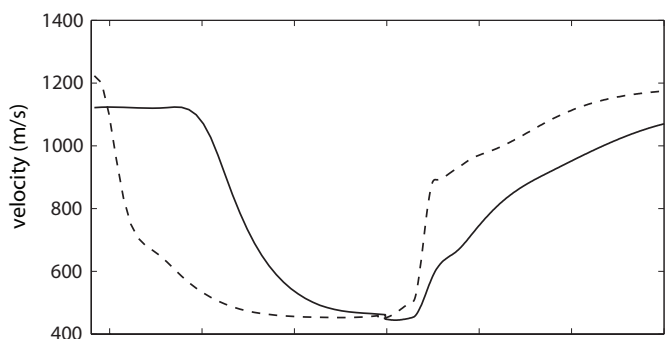

(b)

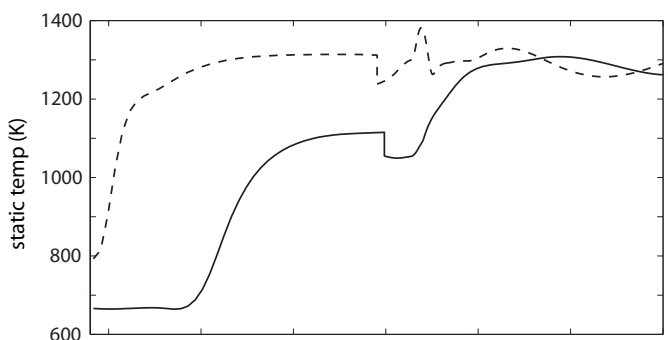

(c)

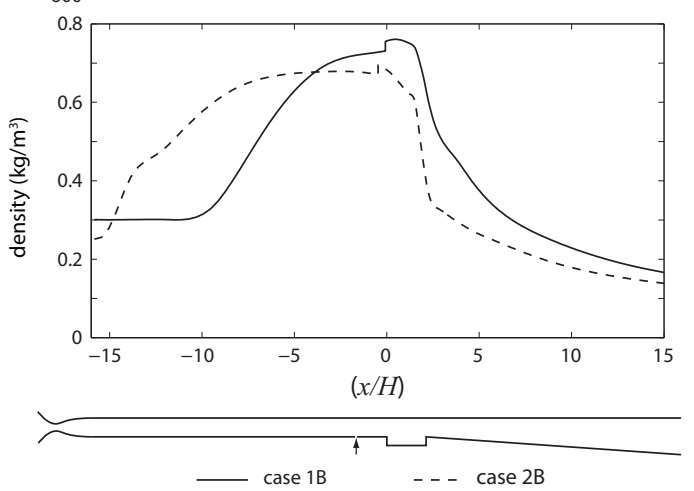

Figure 9. Distribution of flow variables calculated by the 1-D data analysis model (from the measured wall pressure) for cases $1 \mathrm{~B}$ and $2 \mathrm{~B}$.
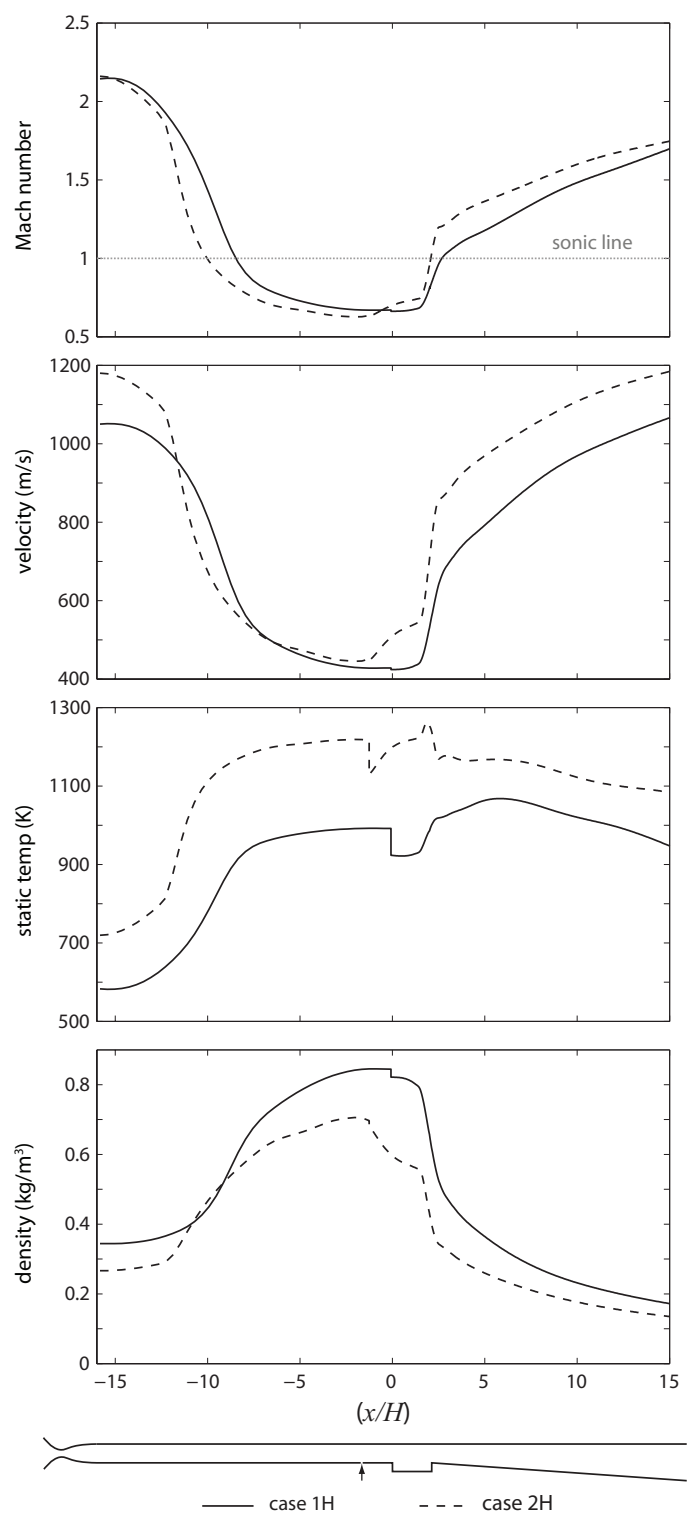

Figure 10. Distribution of flow variables calculated by the 1-D data analysis model (from the measured wall pressure) for cases $1 \mathrm{H}$ and $2 \mathrm{H}$. 


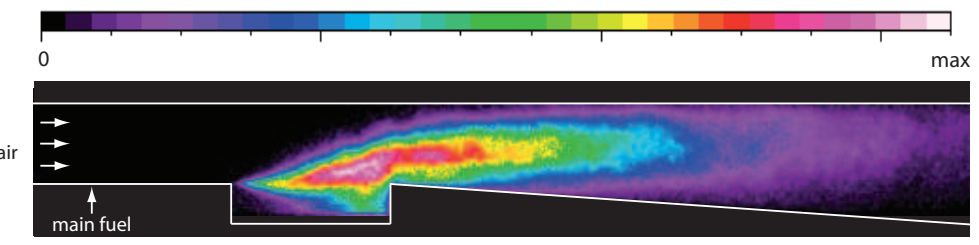

(a) Case 1B.

air

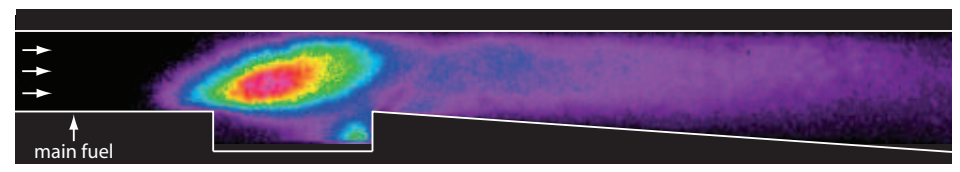

(b) Case 2B.

Figure 11. Mean $\mathrm{CH}^{*}$ luminosity for case $1 \mathrm{~B}$ and 2B conditions.

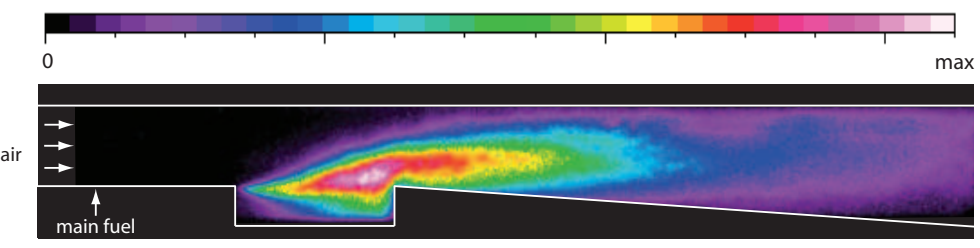

(a) Case 1B.

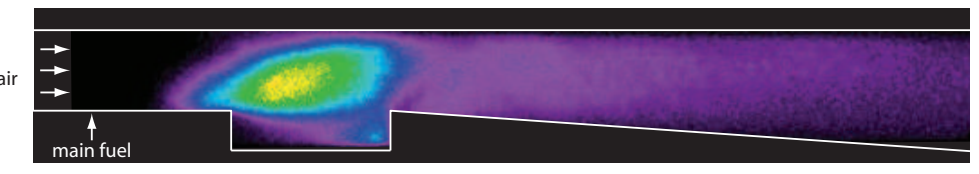

(b) Case 2B.

Figure 12. Mean $\mathrm{OH}^{*}$ luminosity for case $1 \mathrm{~B}$ and 2B conditions.

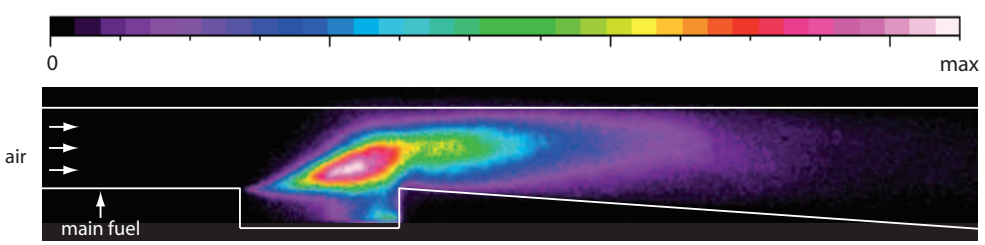

(a) Case $1 \mathrm{H}$.

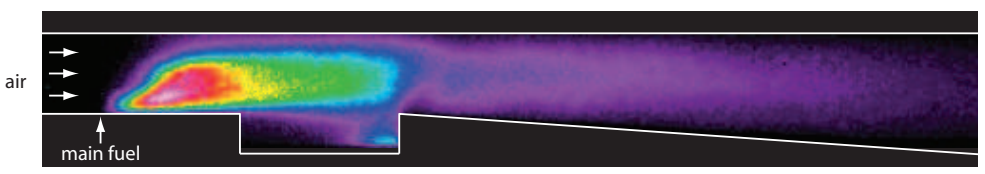

(b) Case $2 \mathrm{H}$.

Figure 13. Mean $\mathrm{OH}^{*}$ luminosity for case $1 \mathrm{H}$ and $2 \mathrm{H}$ conditions. 


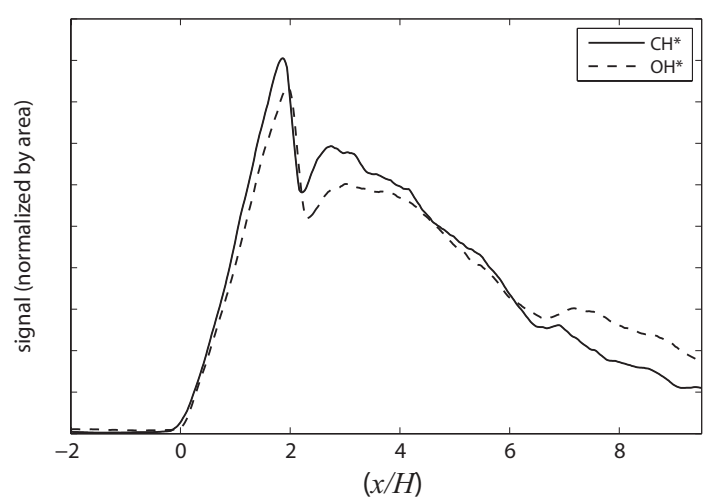

(a) Case 1B.

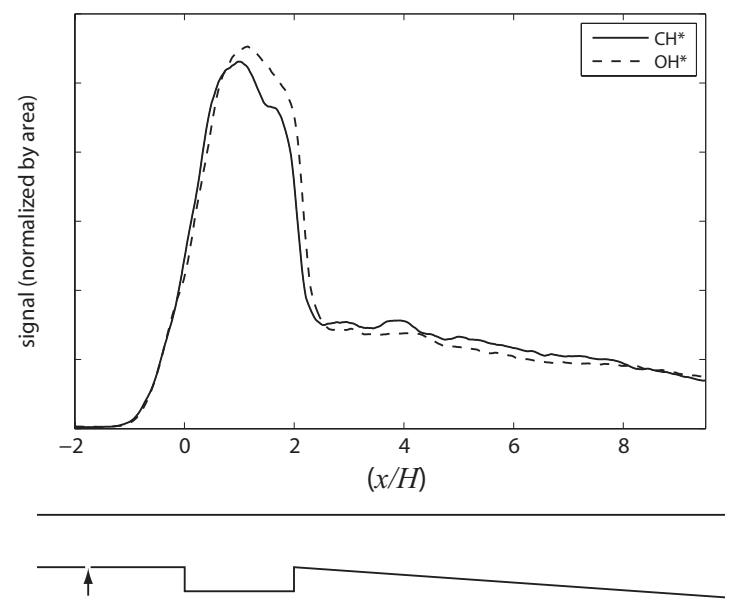

(b) Case 2B.

Figure 14. 1-D $\mathrm{CH}^{*}$ and $\mathrm{OH}^{*}$ signals for cases 1B and 2B. Signals are normalized by the area under the curve.

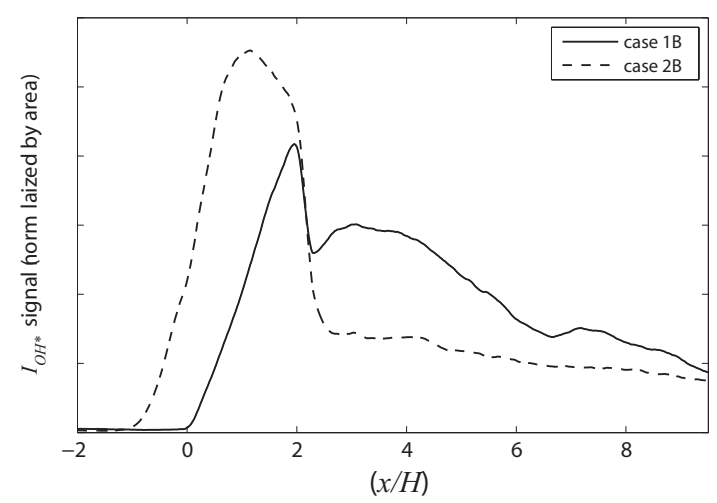

(a) Blended fuel (case 1B and 2B).

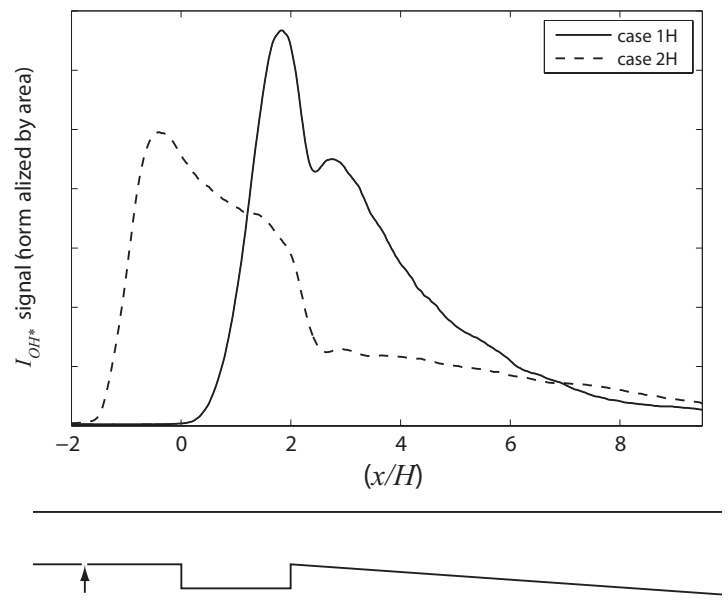

(b) Hydrogen fuel (cases $1 \mathrm{H}$ and $2 \mathrm{H}$ ).

Figure 15. 1-D $\mathrm{OH}^{*}$ signals for cases 1B, 2B, 1H, and $2 \mathrm{H}$. Signals are normalized by the area under the curve. 


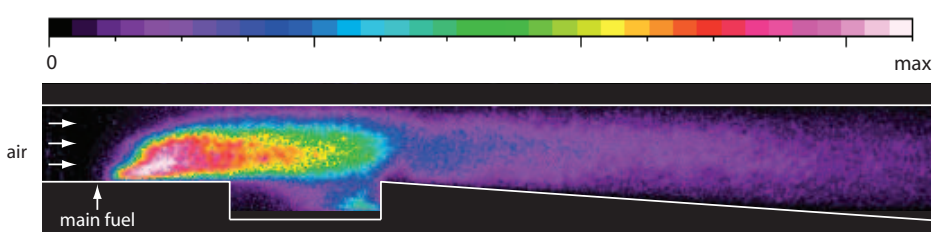

(a) $T_{0}=1520 \mathrm{~K}$.

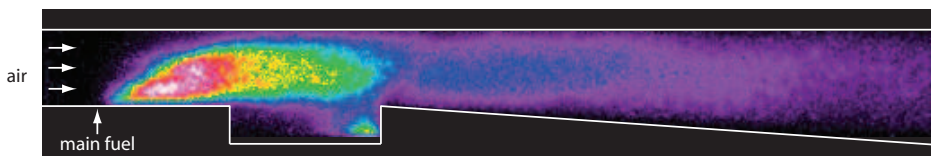

(b) $T_{0}=1410 \mathrm{~K}$.

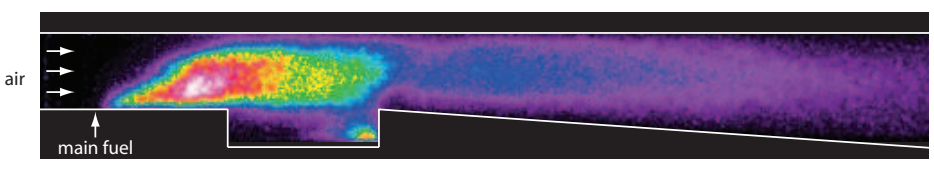

(c) $T_{0}=1270 \mathrm{~K}$.

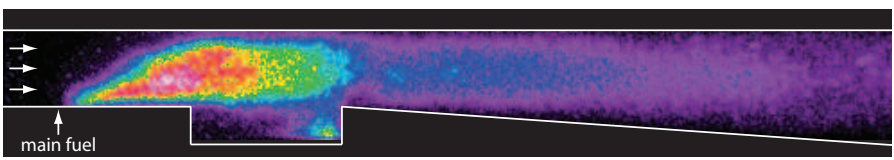

(d) $T_{0}=1220 \mathrm{~K}$

Figure 16. Mean $\mathrm{OH}^{*}$ luminosity for data set $\mathrm{A}$ conditions.

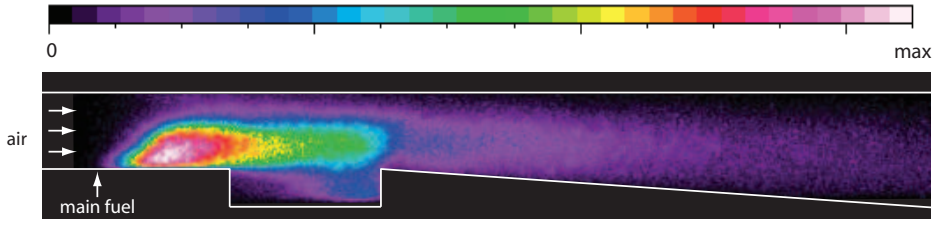

(a) $\phi=0.23$.

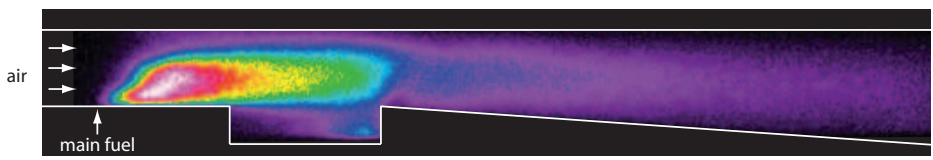

(b) $\phi=0.26$.

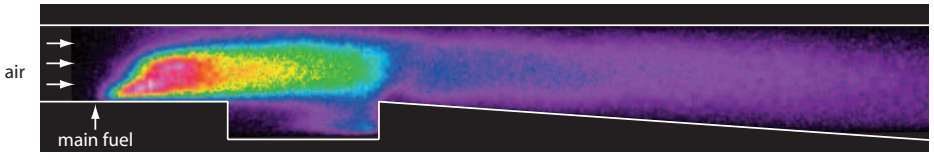

(c) $\phi=0.30$.

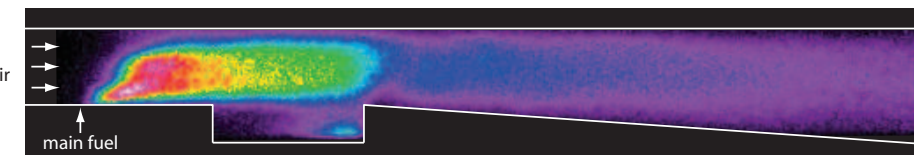

(d) $\phi=0.36$.

Figure 17. Mean $\mathrm{OH}^{*}$ luminosity for data set B conditions. 


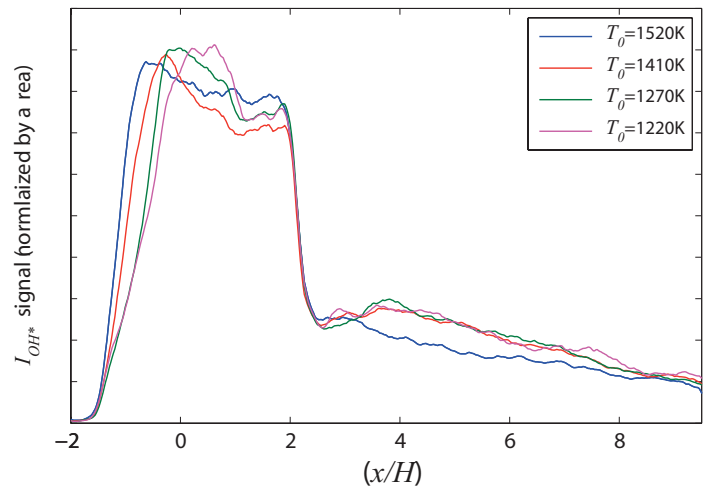

(a) Including cavity signal.
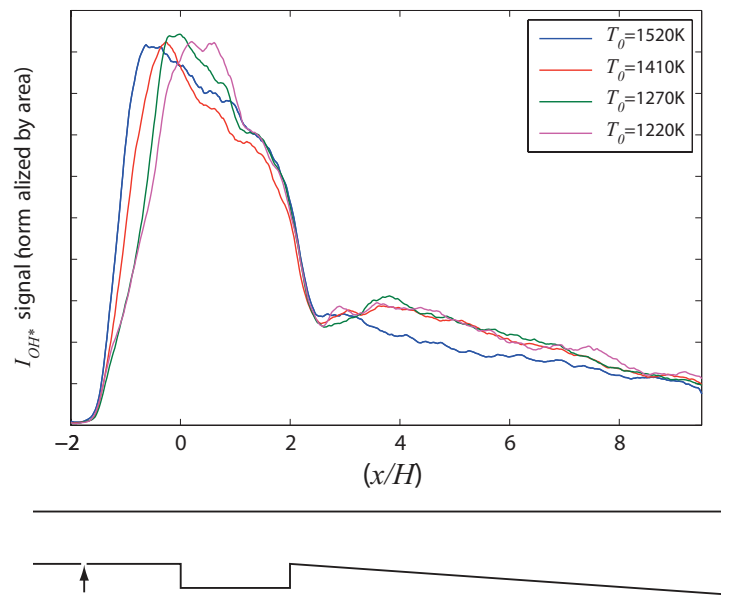

(b) Excluding cavity signal.

Figure 18. 1-D OH* signals for data set $\mathrm{A}$ with and without the signal from the wall cavity included. $T_{0}$ is varied. Signals are normalized by the area under the curve.

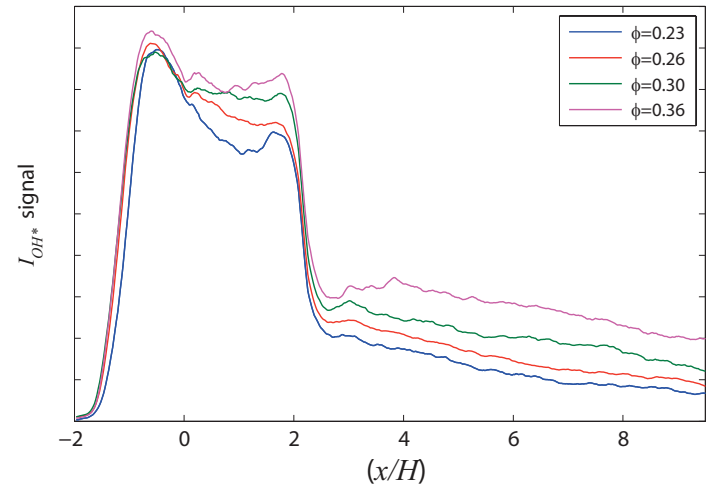

(a) Including cavity signal.
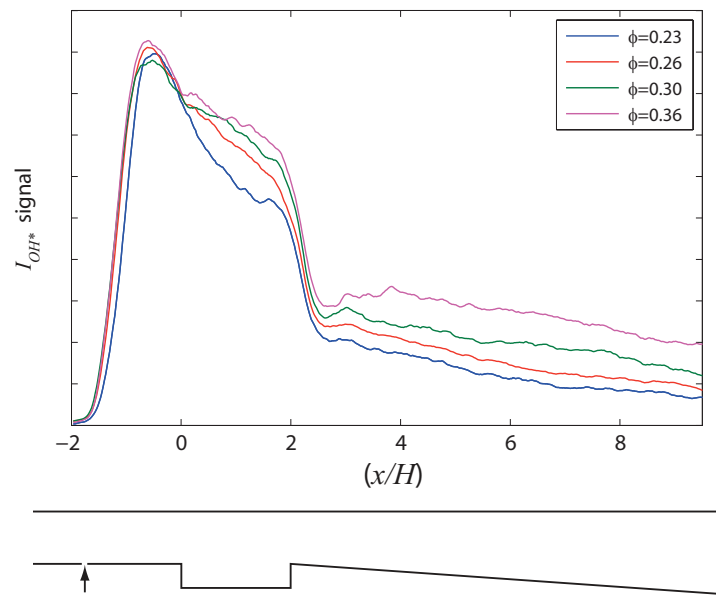

(b) Excluding cavity signal.

Figure 19. 1-D OH* signals for data set $\mathrm{B}$ with and without the signal from the wall cavity included. Equivalence ratio is varied. 

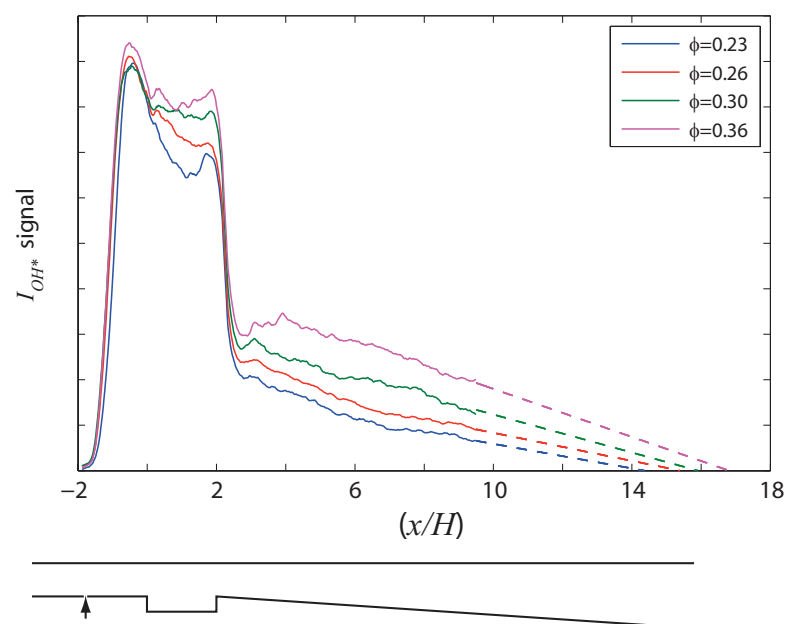

Figure 20. 1-D $\mathrm{OH}^{*}$ signal for data set B (solid lines) and extrapolated linear best fit lines (dashed lines). Data was acquired up to the end of the window at approximately $x / H=9.5$. Linear regression lines fit to the data from $x / H=\mathbf{5 . 5}$ to $\mathbf{9 . 5}$ are shown as dashed lines for $x / H>9.5$.

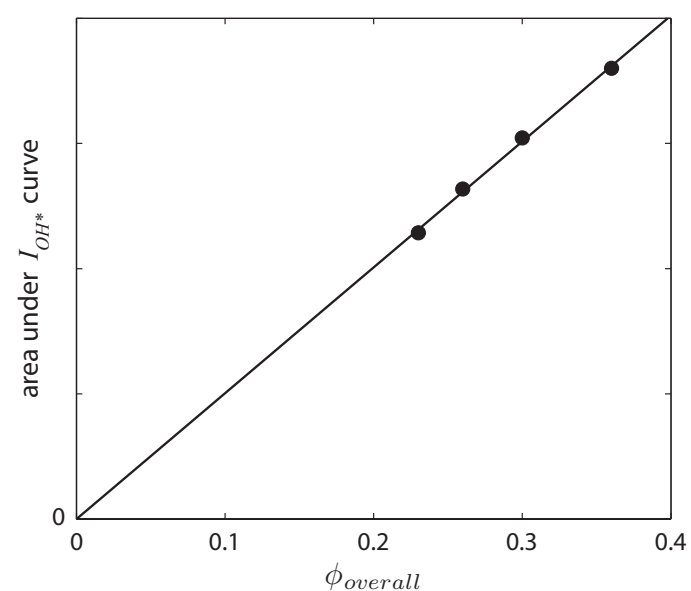

Figure 21. Total area under the extrapolated $\mathrm{OH}^{*}$ curves in Fig. 20 vs. $\phi$. A linear regression fit which passes through origin is shown as a solid line.

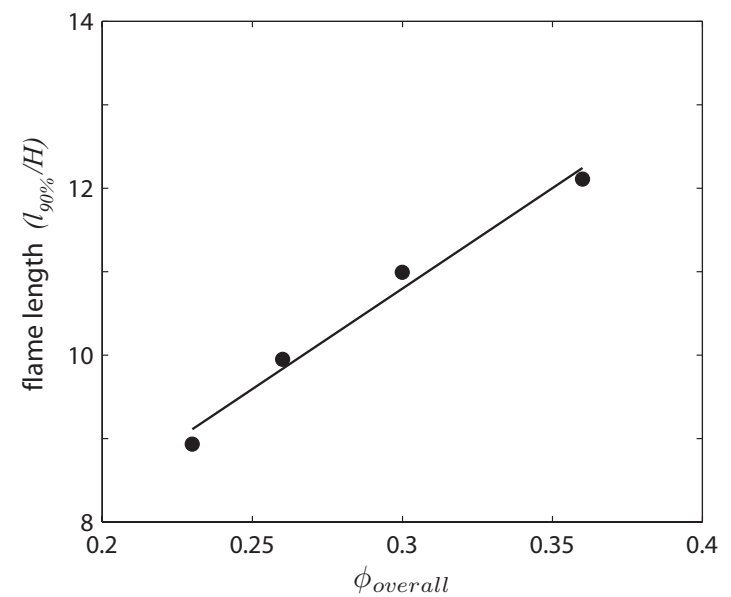

Figure 22. Measured flame length vs. $\phi$ for data set B conditions. The flame length $l_{90 \%}$ is the distance between the fuel injection location and the location where the area under the $\mathrm{OH}^{*}$ curve shown in Fig. 20 is $90 \%$ of the total area. This is approximately equal to the length it takes for $90 \%$ of the heat release to occur. A linear regression fit is shown as a solid line. 

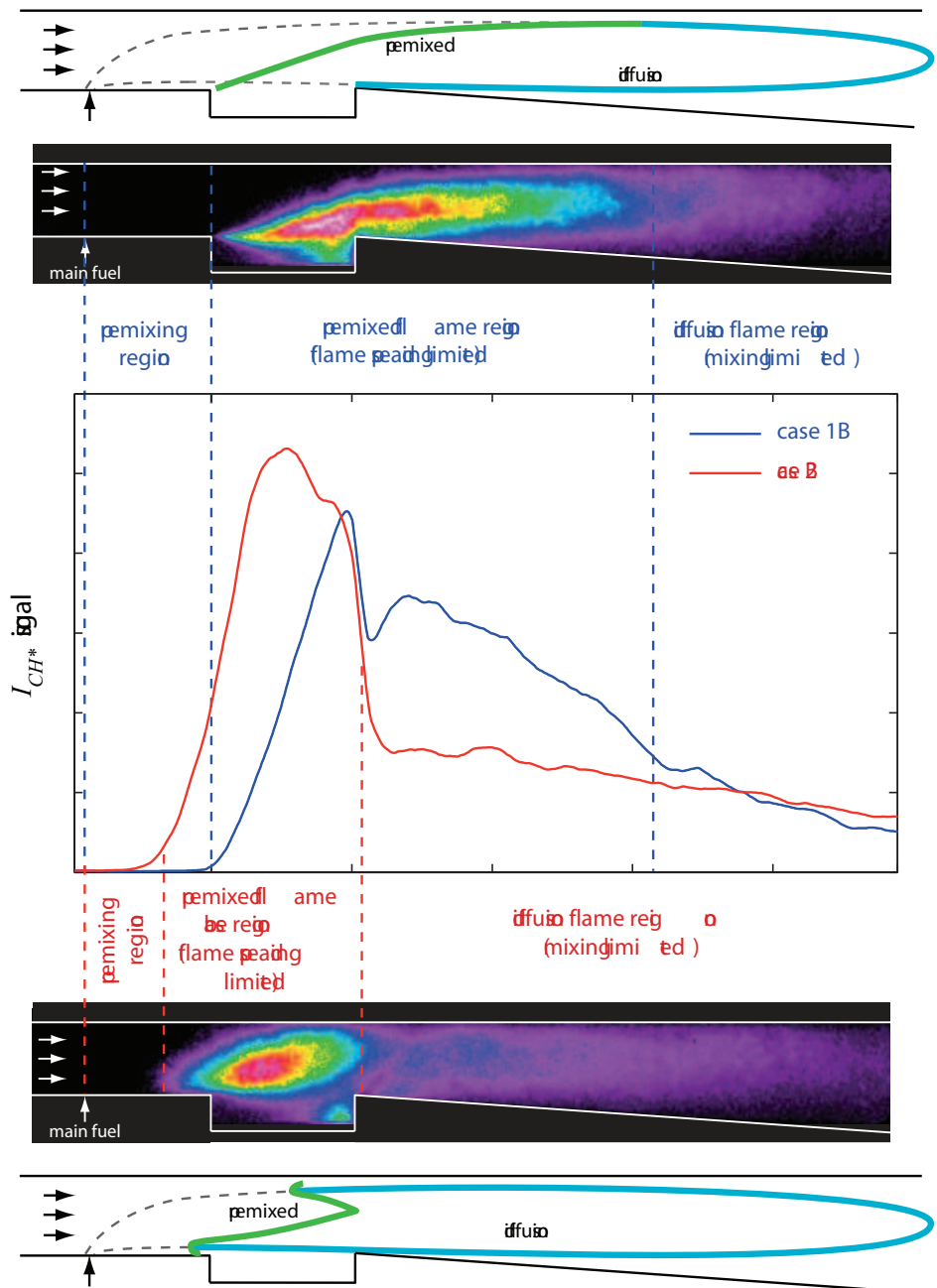

Figure 23. Illustration of the factors limiting the heat release rate in different regions for cavity (case 1B) and jet-wake stabilized combustion (case 2B).

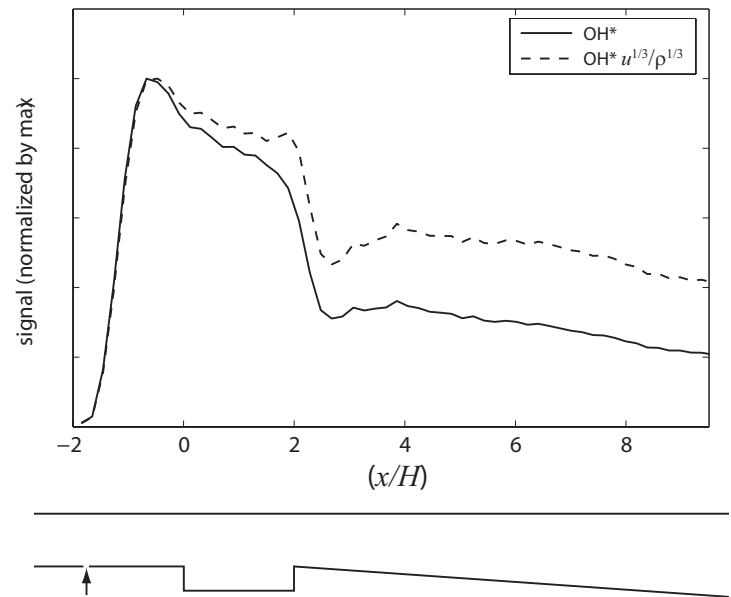

(a) Set $\mathrm{B}, \phi=0.36$.

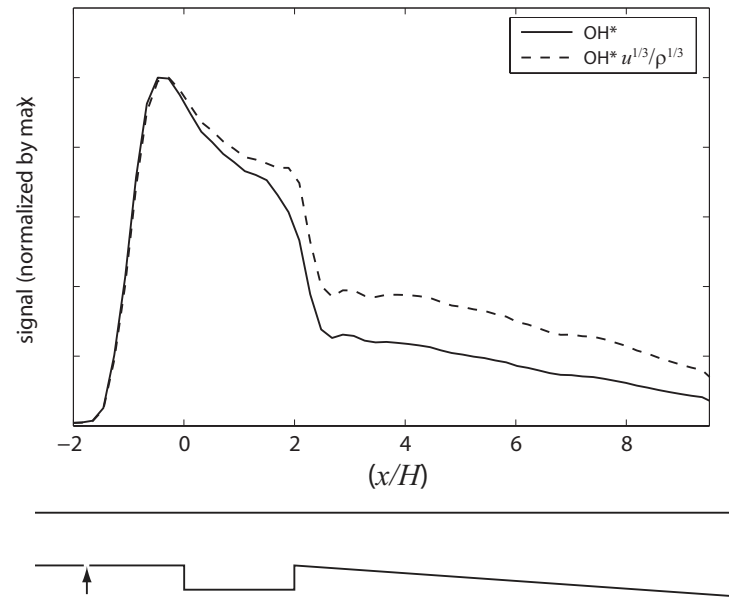

(b) Case $2 \mathrm{H}$.

Figure 24. 1-D OH* signals with and without the co-flow mixing correction applied. Cavity reaction excluded. 

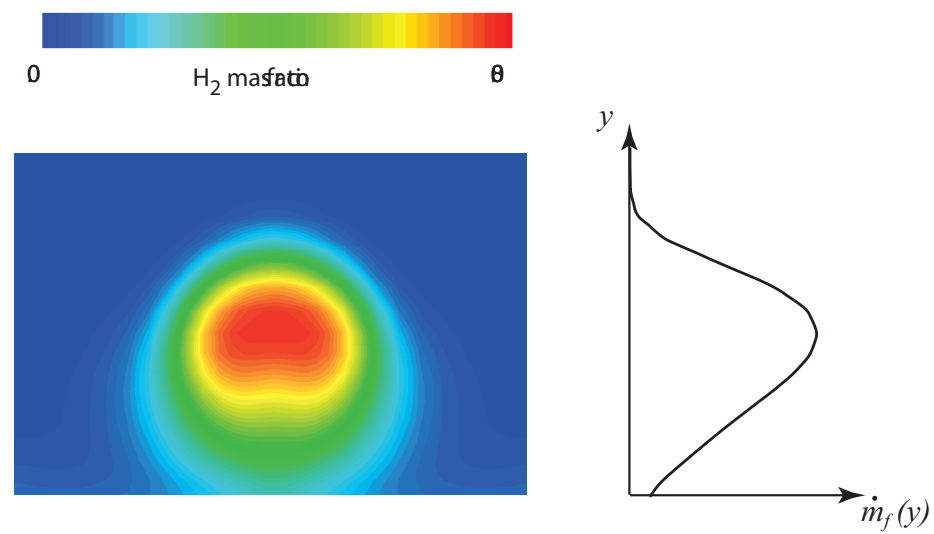

Figure 25. Fuel distribution in the jet-wake cross section ( $y-z$ plane) at $x / H=1$ as computed by non-reacting CFD ++ at case $1 \mathrm{H}$ conditions. The fuel mass flow rate per unit height through this plane $\left(\dot{m}_{f}(y)\right)$ is also shown.

\section{References}

${ }^{1}$ Heiser, W. H. and Pratt, D. T., Hypersonic Airbreathing Propulsion, AIAA Education Series, AIAA, 1994.

${ }^{2}$ Heiser, W. H. and Pratt, D. T., "Aerothermodynamics of the dual-mode combustion system," Scramjet Propulsion, edited by E. T. Curran and S. N. B. Murthy, AIAA, 2000, pp. 569-595.

${ }^{3}$ Torrez, S. M., Driscoll, J. F., Dalle, D. J., and Micka, D. J., "Scramjet engine model masiv: role of mixing chemistry and wave interactions," AIAA/ASME/SAE/ASEE Joint Propulsion Conference, 2009, AIAA-2009-4939.

${ }^{4}$ Ben-Yakar, A. and Hanson, R. K., "Cavity flame-holders for ignition and flame stabilization in scramjets: an overview," J. Prop. Power, Vol. 17, No. 4, 2001, pp. 869-877.

${ }^{5}$ Mathur, T., Gruber, M., Jackson, K., Donbar, J., Donaldson, W., Jackson, T., and Billig, F., "Supersonic combustion experiments with a cavity based fuel injector," J. Prop. Power, Vol. 17, No. 6, 2001, pp. 1305-1312.

${ }^{6}$ Gruber, M. R., Donbar, J. M., Carter, C. D., and Hsu, K.-Y., "Mixing and combustion studies using cavity-based flameholders in a supersonic flow," J. Prop. Power, Vol. 20, No. 5, 2004, pp. 769-778.

${ }^{7}$ Micka, D. J. and Driscoll, J. F., "Combustion characteristics of a dual-mode scramjet combustor with cavity flameholder," Proc. Comb. Inst., Vol. 32, 2009, pp. 2397-2404.

${ }^{8}$ Price, R. B., Hule, I. R., and Sugden, T. M., "Optical studies of the generation of noise in turbulent flames," Proc. Comb. Inst., Vol. 12, 1968, pp. 1093-1102.

${ }^{9}$ Najm, H. N., Paul, P. H., Mueller, C. J., and Wycokoff, P. S., "On the adequacy of certain experimental observables as measurements of flame burning rate," Combust. Flame, Vol. 113, 1998, pp. 312-332.

${ }^{10}$ Hardalupas, Y. and Orain, M., "Local measurements of the time-dependent heat release rate and equivalence ratio using chemiluminescent emmission from a flame," Combust. Flame, Vol. 139, 2004, pp. 188-2007.

${ }^{11}$ Meier, W., Weigand, P., Duan, X. R., and Giezendanner-Thoben, R., "Detailed characterization of the dynamics of thermoacoustic pulsations in a lean premixed swirl flame," Combust. Flame, Vol. 150, 2007, pp. 2-26.

${ }^{12}$ Haber, L. C. and Vandsburger, U., "A global reaction model for $\mathrm{OH}^{*}$ chemiluminescence applied to a laminar flat-flame burner," Combust. Sci. Tech., Vol. 175, 2003, pp. 1859-1891. 753.

${ }^{13}$ Wohl, K. and Welty, F., "Spectrophotometric traverses through flame fronts," Proc. Comb. Inst., Vol. 5, 1954, pp. 746-

${ }^{14}$ Tomioka, S., Murakami, A., Kudo, K., and Mitani, T., "Combustion tests of a staged supersonic combustor with a strut," J. Prop. Power, Vol. 17, No. 2, 2001, pp. 293-300.

${ }^{15}$ Donbar, J., Powell, O., Gruber, M., and Jackson, T., "Post-test analysis of flush-wall fuel injection experiments in a scramjet combustor," AIAA Joint Propulsion Conference, 2001, AIAA 2001-3197.

${ }^{16}$ Han, D. and Mungal, M. G., "Direct measurement of entrainment in reacting/nonreacting turbulent jets," Combust. Flame, Vol. 124, No. 3, 2001, pp. 370-386.

${ }^{17}$ Hasselbrink, E. F. and Mungal, M. G., "Transverse jets and jet flames. Part 1. Scaling laws for strong transverse jets," J. Fluid Mech., Vol. 443, 2001, pp. 1-25.

${ }^{18}$ Hasselbrink, E. F. and Mungal, M. G., "Transverse jets and jet flames. Part 2. Velocity and OH field imaging," J. Fluid Mech., Vol. 443, 2001, pp. 27-68.

${ }^{19}$ Torrez, S. M., Scholten, N. A., Micka, D. J., Driscoll, J. F., Bolender, M. A., Doman, D. B., and Oppenheimer, M. W., "A scramjet engine model including effects of precombustion shocks and dissociation," AIAA/ASME/SAE/ASEE Joint Propulsion Conference, 2008, AIAA-2008-4619. 